\title{
Back to the Future: Molecular Biology Meets Metabolism
}

\author{
Steven L. MCKnight \\ Department of Biochemistry, UT Southwestern Medical Center, Dallas 75390-9152 \\ Correspondence: Steven.Mcknight@UTSouthwestern.edu
}

\begin{abstract}
As biological scientists we aspire to understand how organisms, organs and cells work. Whenever it is possible to hone things down in a reductionist manner to a single metabolite, protein, RNA, or gene, the chances for simplicity and clarity are enhanced. This "reductionist" approach has been wildly successful over the past halfcentury, and there is no reason to cast doubt on its future utility. In contrast, all of us know that molecules do not operate in isolation, and that the robustness of life can be attributed to the web of interactions formed among the substances from which we are made. The orchestration of this web holds the keys to our ultimate understanding of biology. The 76th Annual Cold Spring Harbor Symposium on Quantitative Biology brought together two groups of scientists that seldom self-attract, molecular biologists and physiologists. I saw this event as confirmation that we now recognize that the webs we are seeking to connect and understand will be composed equally of chemicals (metabolites) and polymers (proteins, RNAs and genes).
\end{abstract}

Historically, the field of physiology - as prosecuted with focus on nutrient metabolism-formed a cornerstone for the foundation of modern genetics and the successful reductionism of molecular biology. The single largest leap forward in the field of post-Mendelian genetics came from the studies of Archibald Garrod, who deduced the relationship between gene and enzyme in his seminal studies of inborn errors of metabolism (Garrod 1923). By decades the work of Garrod preceded the seminal, one gene:one enzyme, discoveries of Beadle and Tatum (1941). It is notable that the latter science also focused on metabolism - more specifically, the pathways used by Neurospora crassa to synthesize amino acids. Some 20 years later, Jacob and Monod conceptualized the operon theory of bacterial gene expression, wherein promoters, operators and repressors were presciently hypothesized (Jacob and Monod 1961). It was the ability of Escherichia coli to induce catabolism of lactose as an alternative carbon source to glucose that framed the classical studies illuminating the essence of bacterial gene regulation.

The field of molecular biology began its dominance some four decades ago, and has continued to prosecute science at the interface of metabolism and genetics. So powerful were the techniques, however, that molecular biologists were no longer tied to the metabolic pathways to which they were historically linked. Indeed, one needed to know essentially nothing about metabolism to clone any gene one wanted. Pull-down and yeast two-hybrid experiments can treat metabolism as if it were no more important than tris-(hydroxymethyl)-aminomethane (Tris) buffer. Gene knockouts, in situ hybridizations, immunohistochemical stainings, DNA microarrays, CHIP:Seq, RNA:Seq, and chromosomome capture assays-none of these approaches need pay any mind to the fact that the regulatory state of a cell, organ, or organism must be integrally intertwined with metabolic state. Yes, it is generally appreciated by molecular biologists that the regulatory state of a cell probably has something to do with its metabolic state. In contrast, only recently have we begun to re-awaken to the fact that the reciprocal of this relationship must also be true.

\section{ENZYMES AND SUBSTRATES}

Perhaps a useful starting point for this Symposium overview is an illumination of the contrasting way we think of the relationship of adenosine triphosphate (ATP) as the substrate for protein kinase enzymes as compared with the prototypical relationship between enzymes and substrates. Although classical metabolic enzymes can be regulated in many ways, including rate of synthesis, turnover, and posttranscriptional modification, the major factor controlling the activity of a metabolic enzyme is its access to substrate and product. If substrate levels are high, and products low, the enzyme converts substrate to product. Because many enzymes are reversible, the opposing reaction can happen when substrate levels are low and product high. Contrast this with the operative manner in which most protein kinase enzymes work. With the exception of the adenosine monophosphate (AMP)-activated protein kinase (AMPK), studied so beautifully by Graham Hardie and colleagues (Hardie 2012), the vast majority of protein kinase enzymes could care less about the concentration of their substrate (ATP). These enzymes have evolved to shield themselves from regulation via substrate abundance so that they can instead be regulated by alternative strategies. If a cell had too little ATP to feed its hundreds of protein kinase enzymes, it would be dead. Simply put, protein kinase enzymes are not substrate regulated with respect to ATP. 
Although the distinction between protein kinases and classically studied metabolic enzymes is both simple and obvious, it helps us consider the question of how newly discovered enzymes are regulated. During the symposium a number of presentations were devoted to the study of enzymes that acetylate and de-acetylate polypeptide substrates. Take, for example, the family of histone acetyl transferase (HAT) enzymes that modify chromatin and regulate gene expression in eukaryotic cells. It is generally assumed that these enzymes perform their regulatory task in a manner controlled either by their synthesis, or by their selective recruitment to the right gene at the right time. Like protein kinase enymes, one would never have thought that HAT enzymes might be regulated by the abundance of their substrate, acetyl-coenzyme A (acetyl-CoA). Quite to the contrary, the chapter authored by Benjamin Tu provides compelling evidence that the HAT enzyme component of the Spt-Ada-GCN5 acetyltransferase (SAGA) complex is only activated during a brief window of the yeast metabolic cycle wherein acetylCoA levels exceed the substrate threshold demanded by the relatively high Michaelis constant $\left(K_{\mathrm{m}}\right)$ of the general control of amino acid synthesis 5 (GCN5) HAT enzyme central to the SAGA complex (Cai and Tu 2012).

Why is this important? First, it offers the strong prediction that yeast cells will only be able to commit to growth if they perceive the appropriate abundance of acetyl-CoA. Given that acetyl-CoA is an essential building block for the synthesis of sterols, lipids and other components required for the construction of a new cell, it makes sense that an intracellular pathway might exist to sense acetyl-CoA and gate cellular growth as a distinct regulatory switch. To this end the results of Cai and $\mathrm{Tu}$ were all the more compelling as they demonstrated that this pathway leads to the selective acetylation of histones only on the roughly 1000 "growth genes" within the yeast genome, and only during a transient window wherein acetyl-CoA levels are unusually high - the exact window within which yeast cells make the decision to commit to cell division.

Whether this specific web of interaction between metabolite and signaling switch will be used more broadly in biology remains open to question. What is crystal clear, however, is that the cellular abundance of acetyl-CoA almost certainly serves to regulate the activities of scores of enzymes and pathways in eukaryotic cells. The chapter contributed by Pere Puigserver and colleagues offers clear evidence of nutrient-dependent regulation of metabolic switches and cellular reprogramming via the reversible acetylation of the peroxisome proliferator activated receptor $\gamma$ cofactor $1 \alpha$ (PGC-1 $\alpha)$ (Doniny et al. 2012). Likewise, the beautifully articulated chapter contributed by Eric Verdin and colleagues offers compelling evidence of the logic of reversible acetylation of mitochondrial enzymes as a central regulatory process in the control of physiology as a function of feeding state in mammals (Hirschey et al. 2012).

A similar thought process can be applied to the $O$-linked $\mathrm{N}$-acetylglucosamine ( $\mathrm{O}$-GlcNAc) transferase (OGT) enzyme discovered by Gerald Hart (Hart et al. 2011). OGT dynamically deposits $O$-linked sugars on numerous intracellular proteins, including transcription factors, RNA binding proteins, and signaling proteins. Sugar modification takes place on serine and threonine residues, and in many cases $O$-GlcNAc modification has been shown to compete with phosphorylation. The substrate for the OGT enzyme, $O$-GlcNAc, is made from glucose, acetyl-CoA, and glutamine. Knowing that the levels of these metabolites fluctuate as a function of the nutritional state of cells, it is almost certainly the case that intracellular levels of $O$ GlcNAc also fluctuate according to ambient nutrition. Does the OGT enzyme, like the protein kinase enzymes it competes with, ignore the intracellular levels of its substrate $(O$-GlcNAc) and do its job equivalently irrespective of the metabolic state of a cell? Or is it instead the case that sugar modification of regulatory proteins via OGT and its $O$-GlcNAc substrate is actually tuned to the metabolic state of a cell? If so, one can envision unlimited potential for the cross-coupling of metabolic (sugar modification of serine and threonine residues) and regulatory states (cross-competing phosphorylation of these residues via protein kinase enzymes).

\section{DE-ACETYLASE ENZYMES}

What about the reverse reaction, wherein de-acetylase enzymes remove the acetyl groups from protein substrates? These de-acetylases come in several flavors, one categorized by oxidized nicotinamide adenine dinucleotide $\left(\mathrm{NAD}^{+}\right)$-dependent enzymes, and another typified by $\mathrm{NAD}^{+}$-independent enzymes that require only water for the hydrolysis reaction (de Ruijter et al. 2003; Denu 2005). The former of these categories of de-acetylases, typified by the "sirtuin" family of enzymes, ${ }^{1}$ were the focus of numerous presentations at the 76th Annual Cold Spring Harbor Symposium on Quantitative Biology. In studies ranging from caloric restriction of yeast, worms, and flies, to mammalian circadian rhythm, it was collectively argued that the activity of sirtuins is controlled by the cellular abundance of NAD ${ }^{+}$(Bellet et al. 2012; Canto and Auwerx 2012; Guarente 2012; Ramsey and Bass 2012; Saini et al. 2012; Sun et al. 2012). Many of these studies were focused on de-acetylation reactions associated with gene expression. The idea is simple, appealing, and conceptually concordant with the parallel studies arguing that acetyl-CoA abundance can itself dictate precise patterning of gene expression (Cai and $\mathrm{Tu}$ 2012). Whereas sirtuins clearly rely on $\mathrm{NAD}^{+}$to function in the enzymatic de-acetylation of polypeptide substrates, it remains to be determined whether cellular $\mathrm{NAD}^{+}$levels indeed fluctuate in a sufficiently acute manner to qualify as a regulatory metabolite in this context. More precisely, is the $K_{\mathrm{m}}$ for $\mathrm{NAD}^{+}$substrate for sirtuins properly

\footnotetext{
${ }^{1}$ Wikipedia definition-Sirtuin or Sir2 proteins are a class of proteins that possess either histone deacetylase or mono-ribosyltransferase activity. Sirtuins regulate important biological pathways in bacteria, archea and eukaryotes. The name Sir2 comes from the yeast gene "silent matingtype information regulation 2 ", the gene responsible for cellular regulation in yeast.
} 
matched with ambient, intracellular levels of $\mathrm{NAD}^{+}$, such that the cofactor concentrations actually regulate enzyme activity?

Eric Verdin and colleagues described studies of a sirtuin isoform specifically operative within mitochondria (Hirschey et al. 2012). Proteomic surveys from a variety of laboratories have shown that many mitochondrial enzymes are acetylated (Kim et al. 2006; Wang et al. 2010; Zhao et al. 2010). Mitochondrial function requires the properly orchestrated regulation of the activity of many metabolic enzymes. Mitochondria not only balance metabolic homeostasis, but — as so remarkably demonstrated by Xiaodong Wang and the late Stan Korsmeyer-serve as the ultimate processing center dictating whether a cell is to live or die by programmed cell death. Indeed, the opening lecture of the Symposium, delivered by Doug Wallace, beautifully articulated dynamic changes in the number, morphology, and activity of mitochondria and revealed the importance of this energy-producing organelle in biological processes ranging from aging to neurodegenerative disease and cancer (Wallace 2012). Verdin and colleagues reported that silent mating type information regulator 3 (SIRT3), an $\mathrm{NAD}^{+}$-dependent de-acetylase localized to the mitochondrial matrix, de-acetylates a number of metabolic enzymes in response to fasting or caloric restriction. The beauty of these studies is reflected in the conceptual simplicity of the underlying logic. When a cell, organ, or organism is nutrient limited, the SIRT3 enzyme enhances the activity of acetyl-coenzyme A synthetase, long-chain acyl-coenzyme A dehydrogenase, and 3-hydroxy-3-methyl coenzyme A synthase 2 via direct de-acetylation. That this metabolic adaptation is of physiological relevance, and that depends directly on SIRT3, was clearly demonstrated via studies of laboratory mice bearing a targeted mutation in the gene encoding this mitochondrial enzyme (Hirschey et al. 2012). Viewed according to the $\mathrm{NAD}^{+}$-centric paradigm, these observations would predict that nutrient limitation must lead to an increase in the mitochondrial abundance of $\mathrm{NAD}^{+}$, which would thereby constitute the regulatory step controlling the de-acetylase activity of the SIRT3 enzyme. Time will tell whether or not this prediction is correct.

Whether or not it is accurate to conclude that ambient $\mathrm{NAD}^{+}$levels represent a common control mechanism regulating the activity of the sirtuin family of de-acetylase enzymes, it may be useful to consider several other aspects of this new and exciting domain of science. What, for example, might be the role of the products of the deacetylation reaction? As mentioned in the preceding paragraph, removal of acetyl groups from certain metabolic enzymes has been shown to enhance their activity. As such, one of the products of the reaction - a de-acetylated polypeptide - assumes a new and changed activity state. The other products of sirtuin-mediated deacetylation are nicotinamide and $O$-acetyl-ADP-ribose. It is possible that these products are rapidly equilibrated via intermediary metabolism and, in and of themselves, play no regulatory role. Alternatively, may it be that the unusual $O$-acetylADP-ribose product of sirtuin-mediated de-acetylation could itself constitute a regulatory metabolite?
Metabolic adaptation, including ketogenesis and the production of acetate, is mobilized in the mammalian liver as a function of fasting. SIRT3-mediated deacetylation activates the long-chain acyl-coenzyme A dehydrogenase and 3-hydroxy, 3-methyl-glutaryl-coenzyme A synthase 2 enzymes, thereby offering a means of understanding how starvation increases the production of ketone bodies. Fasting-mediated activation of acetyl-CoA hydrolase also leads to the production of acetate and its liberation from liver tissue. Intriguingly, SIRT3 also deacetylates and activates the mitochondrial enzyme that facilitates anabolic conversion of acetate into acetyl-CoA, acetyl-coenzyme A synthetase 2 (AceCS2). The latter regulatory process of de-acetylase-mediated enzyme activation is evolutionarily conserved from bacteria to mammals, and the underlying mechanism has been resolved by X-ray crystallographic studies (Starai et al. 2002). Activation of the mitochondrial AceCS2, via SIRT3-mediated de-acetylation, can thereby be understood to facilitate metabolic adaptation such that the TCA cycle can be fed in extrahepatic tissues by acetyl-CoA that is produced in an anabolic manner from liver-derived acetate.

Acetylation-mediated regulation of enzyme activity is not limited to mitochondria. K.-L. Guan and colleagues presented evidence that both glycolysis and gluconeogenesis are regulated via the acetylation of rate-limiting enzymes in both pathways. Pyruvate kinase and phosphoenolpyruvate carboxylase are modified by lysine acetylation, in the former case leading to chaperone-mediated autophagy and lysosomal degradation, in the latter case leading to ubiquitylation and subsequent proteosomal degradation (Xiong et al. 2012).

Less attention was paid at the Symposium to the alternative category of $\mathrm{NAD}^{+}$-independent de-acetylase enzymes. These enzymes remove acetyl groups from protein substrates via water-mediated hydrolysis, yielding acetate and de-acetylated proteins as products of the reaction. It is possible that acetate generated via enzymatic de-acetylation of protein substrates might also be used to fuel the anabolic production of acetyl-CoA. Logic would predict that the latter source of acetate might be small. On the other hand, it is formally possible that deposition of acetyl groups on proteins in nutritionally replete cells and organs may-beyond offering regulatory control-constitute a hydrocarbon "savings account" retrievable under conditions of starvation.

\section{RECIPROCITY OF METABOLIC AND REGULATORY STATE}

The fact that regulatory pathways control metabolism was a prominent theme of the Symposium, and I will return to discuss a handful of examples where this understanding may have substantial relevance to cancer. The Sympoisum was also a forum for the communication of scores of examples demonstrating that the reciprocal is equally true - that the metabolic/nutritional state of a cell, tissue or organism can profoundly impact regulatory pathways. The elegant studies of Mike Brown and Joe 
Goldstein have pieced together the pathway by which the cellular abundance of cholesterol regulates the activity state of sterol response element binding protein (SREBP), the transcription factor dedicated to the regulation of cholesterol homeostasis. The underpinnings of this particular paradigm of metabolite-mediated control of regulatory state are sufficiently clear (Brown and Goldstein 1997; Brown et al. 2000) that Brown and Goldstein instead centered their own Symposium presentation on an entirely different scientific topic-the ghrelin-growth hormone axis (Goldstein et al. 2012). The 28-amino-acid ghrelin polypeptide is covalently modified by octanoate (Kojima and Kangawa 2010) via the ghrelin $O$-acyltransferase (GOAT) enzyme (Yang et al. 2008). By comparing the response of wild-type and GOAT-deficient mice with conditions of acute fasting superimposed upon chronic starvation, Brown and Goldstein were able to highlight the importance of ghrelin as a key hormonal signal required for physiological adaptation to starvation.

Prominent among the examples wherein metabolic or physiological state is dominant over regulatory state include Graham Hardie's AMP-regulated protein kinase (Hardie 2012), the hypoxia response pathway elegantly dissected by Greg Semenza, Bill Kaelin and others (Kaelin 2012; Semenza 2012), and the heat shock response pathway and its central role in proteostasis (Morimoto 2012). Hardie's presentation at the Symposium clarified the means by which AMP or adenosine diphosphate (ADP) binding to the $\gamma$ subunit of AMP-activated protein kinase (AMPK) facilitates phosphorylation-mediated activation via the liver kinase B1 (LKB1) tumor suppressor gene product. The anti-anabolic, pro-catabolic regulatory consequences of AMPK activation were shown to be dysfunctional in both cancer cells and viral infection, and it was confirmed that anti-diabetic therapies-including metformin - work by the simple inhibition of mitochondrial ATP production.

The Symposium presentation by Ron Evans offered evidence of a complex web of interaction between AMPK and a host of regulatory pathways (Fan et al. 2012). These include reciprocal influences between AMPK and the core machinery responsible for the control of circadian rhythm (clock, period, and cryptochrome proteins), nuclear hormone receptors, and hepatic transcription factors controlling phenomena ranging from gluconeogenesis to xenobiotic detoxification. Particularly compelling was evidence that the expression of genes encoding nuclear hormone receptors is not only spatially regulated as a function of tissue or cell type, but temporally regulated as a function of a combination of circadian rhythm and feeding state. That certain nuclear receptors, such as those regulated by thyroid hormone, centrally control metabolism is incontrovertible. This theme was echoed by Nicolas Cermakian and colleagues in studies of the estrogenrelated receptor $\alpha$, which was shown to jointly regulate metabolic state and the core components of the mammalian circadian clock (Giguere et al. 2012).

Greg Semenza offered new and unexpected evidence that the HIF $1 \alpha$ transcription factor may interact directly with the M2 isoform of pyruvate kinase (PKM2) often found in cancer cells (Mazurek 2010). The observed interaction was shown to be enhanced by hydroxylation of two proline residues within the defining, alternatively spliced exon of PKM2. Moreover, it was shown that these oxygen-dependent modifications are specified by the same prolyl hydroxylase enzyme known to modify the hypoxia inducible factor (HIF) transcription factors as a consequence of oxygen availability (Semenza 2012). Semenza's observations offer a twist on the exciting PKM2 story of Matthew Vander Heiden, Lew Cantley and Tak Makwhich will be discussed subsequently - offering the possibility that metabolic reprogramming via the HIF transcription factors and M2 isoform of pyruvate kinase may be more intricate and broad-ranging than initially anticipated.

Biological systems must adapt, even in the case of warm-blooded mammals, to subtle changes in body temperature. Central to this adaptation is the heat shock transcription factor (HSF). Rick Morimoto summarized the elegant pathway by which temperature fluctuation, as well as a host of other forms of physiological stress, leads to the conversion of latent, chaperone-bound HSF to the active, trimeric transcription factor. The importance of this adaptive pathway to neurodegenerative disease and aging was comprehensively articulated in the Morimoto presentation and his Symposium chapter (Morimoto 2012). A recent accentuation of the importance of the HSF pathway has been unveiled by the collaborative studies of Ueli Schibler and Joe Takahashi (Kornmann et al. 2007). In a survey of mouse liver mRNAs that continue to cycle with circadian periodicity in the absence of the core circadian clock, Schibler and Takahashi discovered that HSF drives day:night fluctuation in the expression of mRNAs encoding heat shock proteins, nocturnin, the fused in sarcoma RNA binding protein (FUS), and the cold inducible RNA binding protein (CIRBP). Despite differences of only $1.5^{\circ} \mathrm{C}$ over the sleep:wake cycle, the liver tissue of mice responds to HSF-mediated changes in gene expression that are almost certainly of adaptive advantage.

\section{METABOLISM AND CANCER}

A substantial proportion of the Symposium was focused on emerging interest in the relationship between altered metabolic state and cancer. Symposium participants were bombarded with the terms "Warburg effect" and "aerobic glycolysis," and repeatedly reminded that tumors can be effectively imaged by the clinical deployment of ${ }^{18} \mathrm{~F}$ glucose-mediated positron electron tomographic (PET) imaging. The fact that many human tumors are highly glycolytic is an inescapable mantra. Studies of the HIF and myelomatosis viral oncogene (Myc) transcription factors, summarized by Greg Semenza, Bill Kaelin, Chi Dang and others provided compelling evidence that inappropriate expression of these gene regulatory proteins sculpts the metabolic properties of cancer cells. In retrospect, it is perfectly logical to assume that hypoxic cells would seek to orchestrate an adaptive regulatory pathway that would enhance glycolysis - if there is little or no 
oxygen to burn, hypoxic cells will only survive if they can find alternative pathways for the production of ATP other than mitochondrial respiration. Renal cell carcinoma (RCC) tumors constitutively activate the HIF pathway by virtue of elimination of the Von Hipple-Lindau (VHL) syndrome tumor suppressor. The pro-glycolytic effects executed by activated HIF undoubtedly contribute to tumor growth and/or survival.

In the case of Myc, Chi Dang also emphasized the ability of this oncogenic transcription factor to enhance ribosome production (Dang 2012). As a transcription factor Myc activates ribosomal RNA synthesis via RNA polymerase I, as well as mRNAs encoding ribosomal proteins via RNA polymearase II. Indeed, as pointed out by Dang, fruit flies expressing a hypomorphic allele of Myc are composed of small cells and exhibit small body size, just as in the case of the Diminutive mutants defective in the synthesis of ribosomal proteins. The three-way linkage of cancer, metabolism, and translation was highlighted in numerous Symposium presentations focused on the mammalian target of rapamycin (mTOR) pathway. Nahum Sonenberg offered detailed accounting of the intricate web of interactions among eukaryotic translation initiation factor 4E (eIF4E), phosphoinositol 3 kinase (PI3K)/ protein kinase $\mathrm{B}$, mitogen-activated protein kinase (MAPK), and their abilities to inactivate-via mTORthe elongation factor $4 \mathrm{E}$ binding proteins (4E-BPs) that are themselves inhibitors of translation (Topisirovic and Sonenberg 2012). Incontrovertible evidence has confirmed that translational capacity is critically regulated by the metabolic state of a cell. It is equally clear that this regulation is deranged in tumor cells. What remains enigmatic are the identities of the dedicated sensors of key metabolites, such as leucine, methionine and cysteine - what are these sensors and how do they relay their signals to control cell growth?

Symposium presentations delivered by Tak Mak, Craig Thompson, Matthew Vander Heiden, Lew Cantly, Bill Kaelin, and Xiaodong Wang probed regulatory aberrations in tumor cells that lead to metabolic adaptation. Considerable attention was paid to the fact that cancer cells often express an isoform of pyruvate kinase, designated PKM2, that exhibits reduced catalytic activity compared with the enzyme normally expressed in most tissues of adult mammals. The pyruvate kinase enzyme converts phosphoenolpyruvate to pyruvate, leading to the concomitant conversion of ADP to ATP. It was argued that impediments to glycolysis via the expression of PKM2 should enhance sugar flux via the pentose phosphate pathway, thereby favoring the production of $\mathrm{NADP}(\mathrm{H})$. Detailed studies by Mak, Thompson, and Vander Heiden/Cantly further dissected and predicted extensive modifications of metabolic flux in cancer cells, including alterations in the catabolism of glutamine and prediction that cancer cells may actually cause the tricarboxylic acid (TCA) cycle to run in reverse (Cairns et al. 2012; Thompson 2012; Vander Heiden et al. 2012). Whether bona fide tumors in human patients are metabolically adapted in these ways is of critical importance. If so, it is possible that "druggable" enzymatic targets might qualify as control points ripe for the discovery of new anti-cancer therapeutics.

Unequivocally direct evidence that metabolic alterations are of relevance to cancer has begun to emerge from genetic and genomic studies of human tumor samples. Bill Kaelin's Symposium presentation reviewed evidence that mutations affecting the enzymatic activities of fumarate hydratase $(\mathrm{FH})$, succinate dehydrogenase $(\mathrm{SDH})$, and isocitrate dehydrogenase (IDH) centrally drive the formation or viability of certain tumors (Gimenez-Roqueplo et al. 2001; Pollard et al. 2005; Nakamura and Kaelin 2006; Parsons et al. 2008; Kaelin 2012). The FH and SDH mutations can be interpreted to manifest phenotypically as a result of enhanced levels of fumarate and/or succinate. These metabolites competitively inhibit the activities of 2-oxoglutarate-dependent enzymes, including the prolyl-hydroxylase enzyme that inhibits HIF, and a number of related histone and DNA demethylase enzymes atop the regulatory hierarchy controlling epigenetics. Whereas the precise relationship between enhanced levels of fumarate and succinate and the altered regulatory state of cancer cells remains open, there is little question that alteration in metabolism in tumors bearing inactivating mutations in $\mathrm{FH}$ and $\mathrm{SDH}$ is at the heart of the problem.

Perhaps the most exciting and compelling discovery proving that metabolic state can rule the regulatory state of certain human tumors has emerged from Bert Vogelstein's discovery of highly specific mutations in either of the two the IDH isozymes (Parsons et al. 2008). These mutations invariably occur on but one IDH allele. In the case of the cytosolic IDH1 enzyme, the cancer-associated mutations were invariably observed at arginine residue 132 of the polypeptide. For the mitochondrial isozyme, IDH2, cancer-associated mutations were found at either arginine residue 140 or argine residue 172. Instead of simply inactivating the IDH enzyme, the recurrent mutations neomorphically lead to the production of unusually high levels of 2-hydroxyglutarate (Dang et al. 2009). In other words, instead of converting isocitrate to $\alpha$-ketoglutarate, the mutated enzymes yield 2-hydroxyglutarate as a reaction product.

A highly plausible target of 2-hydroxyglutarate is Tet methyl cytosine dioxygenase 2 (TET2), a 2-oxoyglutarate-dependent enzyme that hydroxylates 5-methylcytosine (Figueroa et al. 2010; Xu et al. 2011). Emerging evidence favors DNA demethylation as the ultimate activity of the TET2 enzyme (Noushmehr et al. 2010; Ficz et al. 2011). The inhibitory effects of 2-hydroxyglutarate on the enzymatic activity of TET2 have been demonstrated in biochemical assays, and DNA hypermethylation has been observed in tumor samples bearing IDH mutations. Perhaps most compellingly, mutations in the IDH1/IDH2 and TET2 genes appear to be mutually exclusive in human cancer (Figueroa et al. 2010).

A final example of metabolic adaptation in cancer cells was summarized by Xiaodong Wang. Gain of function mutations in PI3 kinase, and loss of function phosphatase and tensin homolog (PTEN) mutations, activate protein kinase $\mathrm{B}$ - thereby affecting nutrient intake and enhancing translation in cancer cells. As part of this adaptive 
pathway, protein kinase $\mathrm{B}$ enhances the production of a UDPase enzyme localized to the endoplasmic reticulum (ER) that links ATP consumption to enhanced glycolysis. The elevation of ectonucleotide triphosphate diphosphohydrolase 5 (ENTPD5) activity was found to hydrolyze uridine diphosphate (UDP) in the ER to favor $N$-glycosylation and protein folding, thereby protecting protein kinase B-active cancer cells from protein overload, ER stress, and its negative consequences to cancer cell viability (Shen et al. 2012).

\section{PIVOT POINTS CONTROLLING SUGAR METABOLISM}

The 10 enzymes responsible for the catabolic conversion of glucose to lactate were discovered by German and American scientists between 1933 and 1947 (Lohmann 1933; Meyerhof and Lohmann 1934; Kendal and Stickland 1937; Meyerhof and Schultz 1938; Warburg and Christian 1939, 1941; Colowick and Kalckar 1941; Kubowitz and Ott 1943, 1944; Bücher 1947). With one exception, the icons of biochemistry-including Kalckar, Lohmann, Meyerhoff, Warburg, Kubowitz, and Ott-fully solved the enzymatic pathway used by cells to catabolize glucose.

The single shortcoming of these remarkable experimental accomplishments was at the very hub of the glycolytic pathway. The rate limiting enzyme of the pathway, phosphofructokinase (PFK), could only recognize its substrate-fructose-6-phosphate (F-6-P) - at a $K_{\mathrm{m}} 1000$ fold the ambient, physiological level of the enzyme substrate. This enigma stood for nearly 40 years until the discoveries by Belgian and American scientists revealing an allosteric "activating factor" for PFK and the "bifunctional enzyme" that makes and destroys the activating factor (Furuya and Uyeda 1980, 1981; Van Schaftingen et al. 1980, 1981; El-Maghrabi et al. 1981; Uyeda et al. 1981). The activating factor turned out to be fructose-2,6bisphosphate (F-2,6-P), which binds to PFK and increases its affinity for F-6-P 1000-fold. The enzyme that makes and destroys the activating factor, 6-phosphofructo-2-kinase/fructose-2,6-bisphophatase (PFKFB), most aptly termed "bifunctional enzyme," contains both a kinase domain that adds a phosphate onto F-6-P (generating F2,6-P) and a phosphatase domain that regenerates F-6-P. Fittingly, Kosaku Uyeda reported these spectacular discoveries at the 1980 Cold Spring Harbor meeting on Protein Phosphorylation organized by Ed Krebs 30 years ago (Furuya et al. 1981).

Aside slotting in the final piece to complete the puzzle of glycolysis, the discovery of the bifunctional enzyme led to an understanding of the principal manner in which cells regulate glycolysis. Under fasting conditions, glucagon activates cyclic-AMP which, in turn, activates protein kinase A (PKA). Activated PKA phosphorylates an amino-terminal regulatory domain of the bifunctional enzyme, thereby preventing its kinase domain from making the F-2,6-P activator of glycolysis and blocking glucose catabolism at the central, rate-limiting pivot point
(Furuya and Uyeda 1982). How is this reversed when cells or tissues are availed of an ample source of glucose? Because glycolysis is initially blocked via glucagon-mediated phosphorylation of the bifunctional enzyme, newfound glucose is backed up and driven into the pentose phosphate pathway - thereby leading to enhanced levels of 5-carbon sugars. Here comes the beauty of biology: Uyeda and colleagues found that xylulose-5-phosphate, a product of the pentose phosphate pathway, activates protein phosphatase 2A (PP2A) via one of its regulatory subunits, leading to the dephosphorylation and activation of the bifunctional enzyme (Ishikawa et al. 1990). Uyeda went on to clone the genes encoding four different isozymes of the bifunctional enzyme (Algaier and Uyeda 1988), and solved the X-ray crystal structure of one of the isozymes (Hasemann et al. 1996).

Why am I ending this meeting summary chapter on a topic that was hardly even mentioned at the Symposium? I do so because of my belief that regulation of glycolysis via the pathways discovered principally by Uyeda will be of vital importance to cancer. As an example, the various isoforms of the bifunctional enzyme come in flavors that differentially balance phosphatase and kinase activity. Uyeda's placental isoform of the PFKFB enzyme has virile kinase activity, balanced by little or no phosphatase activity - it is hard-wired to produce the F-2,6-P activating factor. This isoform, also called the inducible variant of PFKFB3, is frequently overexpressed in human tumors (Chesney et al. 1999; Atsumi et al. 2002; Bando et al. 2005; Kessler et al. 2008). What better way for a cancer cell to step on the gas and accelerate glycolysis!

Digging deeper, what about the opposite? Karen Vousden offered a masterful Symposium presentation of her discovery of a gene product that she calls TIGAR (TP53induced glycolysis and apoptosis regulator). TIGAR turns out to represent an entirely new isoform of Uyeda's bifunctional enzyme having no kinase activity at all, only the phosphatase activity that destroys the F-2,6-P activating factor (Mor et al. 2012). The interpretation could not be more simple: p53 activates TIGAR as a means of controlling glycolytic flux - perhaps backing up intermediates upstream of F-6-P to feed the pentose phosphate pathway so that damaged cells can be supplied with a replete abundance of NADP(H). In the absence of p53, TIGAR is no longer inducible and-irrespective of the form of damage - the brakes cannot be applied to glycolysis.

Kosaku Uyeda did not stop after solving the final riddle of how cells adapt to short-term variations in the abundance of glucose. He and others knew that prolonged exposure of mammalian cells to an abundant supply of glucose led to the transcriptional activation of genes encoding lipogenic enzymes. These enzymes, including the cytosolic ATP citrate lyase enzyme discovered by Uyeda's long-time colleague, Paul Srere (1959), facilitate the conversion of catabolic products of glycolysis into long-chain fatty acids for the purpose of energy storage. Uyeda was first to purify the long-sought glucose-inducible transcription factor, designated carbohydrate response element binding protein (ChREBP), clone its encoding gene, and prepare and study ChREBP-deficient 
laboratory mice (Yamashita et al. 2001; Iizuka et al. 2004; Uyeda and Repa 2006).

Most satisfyingly, Uyeda discovered that the exact same regulatory logic used to control the short-term regulation of sugar consumption (glycolysis) is also used to control long-term adaptation to glucose abundance (lipogenesis). In the starved state, glucagon activates PKA, leading to phosphorylation of an amino-terminal regulatory domain of ChREBP. This phosphorylation facilitates binding of the transcription factor to $14-3-3$ proteins, ${ }^{2}$ keeping ChREBP in a latent, cytoplasmic state. Upon exposure to a new-found abundance of glucose, the pentose phosphate shunt yields xylulose-5-phosphate, which activates protein phosphatase $2 \mathrm{~A}$. In turn, activated PP2A de-phosphorylates ChREBP, allowing it to move from cytoplasm to nucleus, where it activates the expression of genes encoding lipogenic enzymes (Kabashima et al. 2003).

That the precise same regulatory logic is used to control both the short- and long-term adaptation of cells to glucose abundance is satisfying. It is remarkable that the same scientist-Kosaku Uyeda-solved both of these puzzles. His discoveries revealing the intimate details and common logic of short- and long-term adaptation of cells and tissues to glucose abundance bookend a 30 year era wherein the fields of molecular biology and metabolism have been largely separated. It is hoped that the 76th Cold Spring Harbor Symposium on Quantitative Biology will be looked back upon as the celebratory event putting an end to that extended period of separation.

\section{ACKNOWLEDGMENTS}

I thank Mike Brown for reading this manuscript before publication.

\section{REFERENCES}

Algaier J, Uyeda K. 1988. Molecular cloning, sequence analysis, and expression of a human liver cDNA coding for fructose-6P,2-kinase:fructose-2,6-bisphosphatase. Biochem Biophys Res Commun 153: 328-333.

Atsumi T, Chesney J, Metz C, Leng L, Donnelly S, Makita Z, Mitchell R, Bucala R. 2002. High expression of inducible 6phosphofructo-2-kinase/fructose-2,6-bisphosphatase (iPFK2; PFKFB3) in human cancers. Cancer Res 62: 5881-5887.

Bando H, Atsumi T, Nishio T, Niwa H, Mishima S, Shimizu C, Yoshioka N, Bucala R, Koike T. 2005. Phosphorylation of the 6-phosphofructo-2-kinase/fructose 2,6-bisphosphatase/ PFKFB3 family of glycolytic regulators in human cancer. Clin Cancer Res 11: 5784-5792.

Beadle GW, Tatum EL. 1941. The genetic control of biochemical reactions in Neurospora. Proc Natl Acad Sci 27: 499506.

\footnotetext{
${ }^{2}$ Wikipedia definition - $14-3-3$ proteins are a family of conserved regulatory molecules expressed in all eukaryotic cells. 14-3-3 proteins have the ability to bind a multitude of functionally diverse signaling proteins, including kinases, phosphatases, and transmembrane receptors. More than 100 signaling proteins have been reported as 14-3-3 ligands. The name 14-3-3 refers to the particular elution and migration pattern of these proteins on DEAE-cellulose chromatography and starch-ge electrophoresis. The 14-3-3 proteins eluted in the fourteenth ${ }^{\mathrm{h}}$ fraction $^{-}$ of bovine brain homogenate and were found on position 3.3 of subsequent electrophoresis.
}

Bellet MM, Solis RO, Sahar S, Eckel-Mahan K, Sassone-Corsi P. 2012. The time of metabolism: NAD ${ }^{+}$, SIRT1, and the circadian clock. Cold Spring Harb Symp Quant Biol 76: doi: $10.1101 / \mathrm{sqb} .2011 .76 .010520$.

Brown MS, Goldstein JL. 1997. The SREBP pathway: Regulation of cholesterol metabolism by proteolysis of a membranebound transcription factor. Cell 89: $331-340$.

Brown MS, Ye J, Rawson RB, Goldstein JL. 2000. Regulated intramembrane proteolysis: A control mechanism conserved from bacteria to humans. Cell 100: 391-398.

Bücher T. 1947. Über ein phosphatübertragendes Gärungsferment. Biochim Biophys Acta 1: 292-314.

Cai L, Tu BP. 2012. On acetyl-CoA as a gauge of cellular metabolic state. Cold Spring Harb Symp Quant Biol 76: doi: 10.1101/sqb.2011.76.010769.

Cairns RA, Harris I, McCraken S, Mak TW. 2012. Cancer cell metabolism. Cold Spring Harb Symp Quant Biol 76: doi: $10.11011 / \mathrm{sqb} .2011 .76 .012856$.

Canto C, Auwerx J. 2012. NAD ${ }^{+}$as a signaling molecule modulating metabolism. Cold Spring Harb Symp Quant Biol 76: doi: 10.1101 /sqb.2012.76.010439.

Chesney J, Mitchell R, Benigni F, Bacher M, Spiegel L, AlAbed Y, Han JH, Metz C, Bucala R. 1999. An inducible gene product for 6-phosphofructo-2-kinase with an AU-rich instability element: Role in tumor cell glycolysis and the Warburg effect. Proc Natl Acad Sci 96: 3047-3052.

Colowick SP, Kalckar HM. 1941. Glucose phosphorylation and oxidation in cell-free tissue extracts. J Biol Chem 137: $343-356$

Dang CV. 2012. Therapeutic targeting of myc-reprogrammed cancer cell metabolism. Cold Spring Harb Symp Quant Biol 76: doi: 10.1101/sqb.2011.76.011296.

Dang L, White DW, Gross S, Bennett BD, Bittinger MA, Driggers EM, Fantin VR, Jang HG, Jin S, Keenan MC, et al. 2009. Cancer-associated IDH1 mutations produce 2-hydroxyglutarate. Nature 462: 739-744.

Denu JM. 2005. The Sir2 family of protein deacetylases. Curr Opin Chem Biol 9: 431-440.

de Ruijter AJM, van Gennip AH, Caron HN, Kemp S, van Kuilenberg ABP. 2003. Histone deacetylases (HDACs): Characterization of the classical HDAC family. Biochem $J$ 370: 737-749.

Doniny JE, Gerhart-Hines Z, Puigserver P. 2012. Nutrient-dependent acetylation controls basic regulatory metabolic switches and cellular programming. Cold Spring Harb Symp Quant Biol 76: doi ??.

El-Maghrabi MR, Claus TH, Pilkis J, Pilkis SJ. 1981. Partial purification of a rat liver enzyme that catalyzes the formation of fructose 2,6-bisphosphate. Biochem Biophys Res Commun 101: $1071-1077$.

Fan W, Downes M, Atkins A, Yu R, Evans R. 2012. Nuclear receptors and AMPK: Resetting metabolism. Cold Spring Harb Symp Quant Biol 76: doi ??.

Ficz G, Branco MR, Seisenberger S, Santos F, Krueger F, Hore TA, Marques CJ, Andrews S, Reik W. 2011. Dynamic regulation of 5-hydroxymethylcytosine in mouse ES cells and during differentiation. Nature 473: 398-402.

Figueroa ME, Abdel-Wahab O, Lu C, Ward PS, Patel J, Shih A, Li Y, Bhagwat N, Vasanthakumar A, Fernandez HF, et al. 2010. Leukemic IDH1 and IDH2 mutations result in a hypermethylation phenotype, disrupt TET2 function, and impair hematopoietic differentiation. Cancer Cell 18: $533-$ 567.

Furuya E, Uyeda K. 1980. Regulation of phosphofructokinase by a new mechanism: An activation factor binding to phosphorylated enzyme. J Biol Chem 255: 11656-11659.

Furuya E, Uyeda K. 1981. A novel enzyme catalyzes the synthesis of activation factor from ATP and D-fructose-6-P. J Biol Chem 256: 7109-7112.

Furuya E, Uyeda K. 1982. Regulation of fructose-6-P,2-kinase by phosphorylation and dephosphorylation: A possible mechanism for a coordinated control of glycolysis and glycogenolysis. Proc Natl Acad Sci 79: 325-329. 
Furuya E, Kagimoto T, Uyeda K. 1981. Regulation of liver phosphofructokinase by a combination of phosphorylation and a new activation factor. In Protein phosphorylation (ed. Rosen OM, Krebs EG), Vol. 8, pp. 659-674. Cold Spring Harbor Conferences on Cell Proliferation. Cold Spring Harbor Laboratory, Cold Spring Harbor, NY.

Garrod AE. 1923. Inborn errors of metabolism, 2nd ed. Henry Frowde and Hodder \& Stoughton, London.

Giguere V, Dufour CR, Eichner LJ, Deblois G, Cermakian N. 2012. Estrogen-related receptor $\alpha$, the molecular clock and transcriptional control of metabolic outputs. Cold Spring Harb Symp Quant Biol 76: doi: 10.1101/sqb.2011.76. a011031.

Gimenez-Roqueplo AP, Favier J, Rustin P, Mourad JJ, Plouin PF, Corvol P, Rotig A, Jeunemaitre X. 2001. The R22X mutation of the SDHD gene in hereditary paraganglioma abolishes the enzymatic activity of complex II in the mitochondrial respiratory chain and activates the hypoxia pathway. Am J Hum Genet 69: 1186-1197.

Goldstein JL, Zhao T-j, Li RL, Sherbert DP, Liang G, Brown MS. 2012. Surviving starvation: Essential role of the ghrelingrowth hormone axis. Cold Spring Harb Symp Quant Biol 76: doi: $10.11011 /$ sqb.2011.76.010447.

Guarente L. 2012. Sirtuins, aging and metabolism. Cold Spring Harb Symp Quant Biol 76: doi: 10.1101/sqb.2011.76. a010629.

Hardie DG. 2012. Adenosine monophosphate-activated protein kinase: A central regulator of metabolism with roles in diabetes, cancer, and viral infection. Cold Spring Harb Symp Quant Biol 76: doi: $10.1101 /$ sqb.2011.76.010819.

Hart GW, Slawson C, Ramirez-Correa G, Lagerlof O. 2011. Cross talk between $O$-GlcNAcylation and phosphorylation in signaling, transcription, and chronic disease. Annu Rev Biochem 80: 825-858.

Hasemann CA, Istvan ES, Uyeda K, Deisenhofer J. 1996. Crystal structure of the bifunctional enzyme 6-phosphofructo-2kinase/fructose-2,6-bisphosphatase reveals distinct domain homologies. Structure 4: 1017-1029.

Hirschey MD, Shimazu T, Huang J-Y, Schwer B, Verdin E. 2012. SIRT3 regulates mitochondrial protein acetylation and intermediary metabolism. Cold Spring Harb Symp Quant Biol 76: doi: $10.1101 / \mathrm{sqb} .2011 .76 .010850$.

Iizuka K, Bruick RK, Liang G, Horton JD, Uyeda K. 2004. Deficiency of carbohydrate response element binding protein (ChREBP) reduces lipogenesis as well as glycolysis. Proc Natl Acad Sci 101: 7281-7286.

Ishikawa E, Ogushi S, Ishikawa T, Uyeda K. 1990. Activation of mammalian phosphofructokinases by ribose 1,5-bisphosphate. J Biol Chem 265: 18875-18878.

Jacob F, Monod J. 1961. Genetic regulatory mechanisms in the synthesis of proteins. J Mol Biol 3: 318-356.

Kabashima T, Kawaguchi T, Uyeda K. 2003. Xylulose-5-phosphate activated protein phosphatase is mechanism of hepatic glucose-induced lipogenesis. Proc Natl Acad Sci 100: $5107-$ 5112.

Kaelin WG. 2012. Cancer and altered metabolism: Potential importance of hypoxia-inducible factor and 2-oxoglutaratedependent dioxygenases. Cold Spring Harb Symp Quant Biol 76: doi: $10.1101 / \mathrm{sqb} .2011 .76 .010975$.

Kendal LP, Stickland LH. 1937. The initial stages of glycolysis in muscle extracts. Nature 140: 360-361.

Kessler R, Bleichert F, Warnke JP, Eschrich K. 2008. 6-Phosphofructo-2-kinase/fructose-2,6-bisphosphatase (PFKFB3) is up-regulated in high-grade astrocytomas. J Neurooncol 86: 257-264.

Kim SC, Sprung R, Chen Y, Xu Y, Ball H, Pei J, Cheng T, Kho Y, Xiao H, Xiao L, et al. 2006. Substrate and functional diversity of lysine acetylation revealed by a proteomics survey. Mol Cell 23: 607-618.

Kojima M, Kangawa K. 2010. Ghrelin: From gene to physiological function. Results Probl Cell Differ 50: 185-205.

Kornmann B, Schaad O, Bujard H, Takahashi J, Schibler U. 2007. System driven and ocscillator-dependent circadian transcription in mice with a conditionally active liver clock. PLoS Biol 5: e34.

Kubowitz F, Ott P. 1943. Isolierung und kristallisation eines Garungsfermentes aus Tumoren. Biochem Z 314: 94.

Kubowitz F, Ott P. 1944. Isolierung von garungsfermenten aus menschlichen Muskeln. Biochem Z 317: 193-203.

Lohmann K. 1933. Uber phosphorylierung und dephosphorylierung. Bildung der naturlichen hexosemonophosphorsäure aus ihren komponenten. Biochem Z 262: 137-151.

Mazurek S. 2010. Pyruvate kinase type M2: A key regulator of the metabolic budget system in tumor cells. Int J Biochem Cell Biol 43: 969-980.

Meyerhof O, Lohmann K. 1934. Enzyme equilibrium reaction between hexosediphosphate and dihydroxyacetonephosphate. Biochem Z 271: 89-110.

Meyerhof O, Schultz W. 1938. Eine neue bestimmungsmethode der phosphoglycerinsaure. Biochem Z 297: 60 .

Mor I, Cheung EC, Vousden KH. 2012. Control of glycolysis through regulation of PFK1: Old friends and recent additions. Cold Spring Harbor Symp Quant Biol 76: doi: 10.1101/ sqb.2011.76.010868.

Morimoto RI. 2012. The heat shock response: Systems biology of proteotoxic stress in aging and disease. Cold Spring Harbor Symp Quant. Biol 76: doi ??.

Nakamura E, Kaelin WG. 2006. Recent insights into the molecular pathogenesis of pheochromocytoma and parganglioma. Endocr Pathol 17: 97-106.

Noushmehr H, Weisenberger DJ, Diefes K, Phillips HS, Pujara K, Berman BP, Pan F, Pelloski CE, Sulman EP, Bhat KP, et al. 2010. Identification of a $\mathrm{CpG}$ island methylator phenotype that defines a distinct subgroup of glioma. Cancer Cell 17: 510-522.

Parsons DW, Jones S, Zhang X, Lin JC-S, Leary RJ, Angendent P, Mankoo P, Carter H, Siu I-M, Gallia GL, et al. 2008. An integrated genomic analysis of human glioblastoma multiforme. Science 231: 1807-1812.

Pollard PJ, Briere JJ, Alam NA, Barwell J, Barclay E, Wortham NC, Hunt T, Mitchell M, Olpin S, Moat SJ, et al. 2005. Accumulation of Krebs cycle intermediates and over-expression of HIF $1 \alpha$ in tumours which result from germline FH and SDH mutations. Hum Mol Genet 14: 2231-2239.

Ramsey KM, Bass J. 2012. Circadian clocks in fuel harvesting and energy homeostasis. Cold Spring Harbor Symp Quant Biol 76: doi: 10.1101/sqb.2011.76.010546.

Saini C, Suter DM, Liani A, Gos P, Schibler U. 2012. The mammalian circadian timing system: Synchronization of peripheral clocks. Cold Spring Harbor Symp Quant Biol 76: doi: 10.1101/sqb.2011.76.010918

Semenza GL. 2012. Regulation of metabolism by hypoxia-inducible factor 1. Cold Spring Harb Symp Quant Biol 76: doi: 10.1101/sqb.2011.76.010678.

Shen Z, Huang S, Fang M, Wang X. 2012. ENTPD5, and endoplasmic reticulum UDPase, alleviates ER stress induced by protein overloading in AKT-activated cancer cells. Cold Spring Harb Symp Quant Biol 76: doi: 10.1101/sqb.2011. $76 \mathrm{a} 010876$.

Srere PA. 1959. The citrate cleavage enzyme: I. Distribution and purification. J Biol Chem 234: 2544-2547.

Starai VJ, Celic I, Cole RN, Boeke JD, Escalante-Semerena JC. 2002. Sir2-dependent activation of acetyl-CoA synthetase by deacetylation of active lysine. Science 298: 2390-2392.

Sun Z, Feng D, Everett LJ, Bugge A, Lazar MA. 2012. Circadian epigenomic remodeling and hepatic lipogenesis: Lessons from HDAC3. Cold Spring Harb Symp Quant Biol 76: doi: 10.1101/sqb.2011.76.011494.

Thompson CB. 2012. Rethinking the regulation of cellular metabolism. Cold Spring Harb Symp Quant Biol 76: doi ??.

Topisirovic I, Sonenberg N. 2012. mRNA translation and energy metabolism in cancer: The role of the MAPK and mTORCI pathways. Cold Spring Harb Symp Quant Biol 76: doi: 10.1101/sqb.2011.76.a010785.

Uyeda K, Repa JJ. 2006. Carbohydrate response element binding protein, ChREBP, a transcription factor coupling hepatic 


\section{BACK TO THE FUTURE}

glucose utilization and lipid synthesis. Cell Metab 4: $107-$ 110.

Uyeda D, Furuya E, Sherry AD. 1981. The structure of "activation factor" for phosphofructokinase. J Biol Chem 256: 8679-8684.

Vander Heiden MG, Lunt SY, Dayton TL, Fiske BP, Israelsen WJ, Mattaini KR, Vokes NI, Stephanopoulos G, Cantley LC, Metallo CM, et al. 2012. Metabolic pathway alterations that support cell proliferation. Cold Spring Harb Symp Quant Biol 76: doi: $10.1101 / \mathrm{sqb} .2012 .76 .010900$.

Van Schaftingen E, Hue L, Hers HG. 1980. Fructose-2,6bisphosphate, the probable structure of the glucose and glucagon-sensitive stimulator of phosphofructokinase. Biochem J 192: 897-907.

Van Schaftingen E, Jett M, Hue L, Hers HG. 1981. Control of liver 6-phosphofructokinase by fructose-2,6-biphosphate and other effectors. Proc Natl Acad Sci 78: 4383-4386.

Wallace D. 2012. Bioenergetic origins of complexity and disease. Cold Spring Harb Symp Quant Biol 76: doi: 10.1101/ sqb.2011.76.010462.

Wang Q, Zhang Y, Yang C, Xiong H, Lin Y, Yao J, Li H, Yao LY, Ning Z, Zeng R, et al. 2010. The acetylation of metabolic enzymes coordinates carbon source and metabolic flux. Science 327: 1004-1007.
Warburg O, Christian W. 1939. Protein moiety of the carbohydrate-oxidizing enzyme of fermentation. Biochem $Z$ 301: $221-222$.

Warburg O, Christian W. 1941. Isolation and crystallization of enolase. Naturwissenschaften 29: 589-590.

Xiong Y, Lei Q-Y, Zhao S, Guan K-L. 2012. Regulation of glycolysis and gluconeogenesis by acetylation of PKM and PEPCK. Cold Spring Harb Symp Quant Biol 76: doi: 10.1101/sqb.2011.76.010942.

Xu W, Yang H, Liu Y, Yang Y, Wang P, Kim SH, Ito S, Yang C, Xiao MT, Liu LX, et al. 2011. Oncometabolite 2-hydroxyglutarate is a competitive inhibitor of $\alpha$-ketoglutarate-dependent dioxygenases. Cancer Cell 19: 17-30.

Yamashita H, Takenoshita M, Sakurai M, Bruick RK, Henzel WJ, Shillinglaw W, Arnot D, Uyeda K. 2001. A glucoseresponsive transcription factor that regulates carbohydrate metabolism in the liver. Proc Natl Acad Sci 98: 9116-9121.

Yang J, Brown MS, Liang G, Grishin NV, Goldstein JL. 2008. Identification of the acyltransferase that octanolylates ghrelin, an appetite-stimulating peptide hormone. Cell 132: 387-396.

Zhao S, Xu W, Jiang W, Yu W, Lin Y, Zhang T, Yao J, Zhou L, Zeng Y, Li H, et al. 2010. Regulation of cellular metabolism by protein lysine acetylation. Science 327: 1000-1004. 


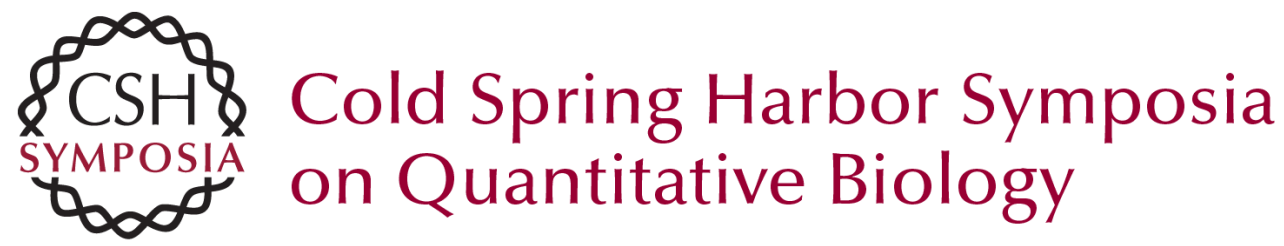

\section{Back to the Future: Molecular Biology Meets Metabolism}

Steven L. McKnight

Cold Spring Harb Symp Quant Biol 2011 76: 403-411 originally published online April 17, 2012 Access the most recent version at doi:10.1101/sqb.2012.76.013722

References This article cites 79 articles, 21 of which can be accessed free at: http://symposium.cshlp.org/content/76/403.full.html\#ref-list-1

\section{License}

Email Alerting Receive free email alerts when new articles cite this article - sign up in Service the box at the top right corner of the article or click here. 